\title{
MANAJEMEN PERUBAHAN DI PEMERINTAH DAERAH PROVINSI SULAWESI TENGAH
}

\author{
PRICYLIA CHINTYA DEWI BUNTUANG \\ Jurusan Manajemen, Fakultas Ekonomi, Universitas Tadulako \\ Email: pricyliabuntuang@yahoo.com
}

\begin{abstract}
This study aims to know and analyze of the description implementation of change management in Central Sulawesi Provincial Government. The method used in this research is descriptive. This research was conducted at work unit of local government area of Central Sulawesi Province with unit of employee analysis. . Data were obtained using observation, questionnaire and documentation. The sample of the study amounted to 308 respondents determined by stratified random sampling technique. The results show that the implementation of change management in the Central Sulawesi Provincial Government has been implemented based on the model developed by Kurt Lewin which consists of unfreezing, changing and refreezing, where the research results show that the most influential aspect in shaping change management in Central Sulawesi Province is the refreezing aspect which states that employees create / maintain change, while the weakest aspect in influencing change management is unfreezing caused employees are less ready to face changes even employees less open themselves to changes made by the organization in this case the unit of work area .
\end{abstract}

Keywords: Management, change, organization.

\begin{abstract}
ABSTRAK
Penelitian ini bertujuan untuk mengetahui dan menganalisis deskripsi pelaksanaan manajemen perubahan di Pemerintah Daerah Provinsi Sulawesi Tengah. Metode yang digunakan pada penelitian adalah deskriptif. Penelitian ini dilakukan di satuan kerja perangkat daerah Pemerintah Daerah Provinsi Sulawesi Tengah dengan unit analisis pegawai. Data diperoleh dengan menggunakan observasi, kuesioner dan dokumentasi. Sampel penelitian berjumlah 308 responden yang ditentukan dengan teknik stratified random sampling. Hasil penelitian menunjukkan bahwa pelaksanaan manajemen perubahan di Pemerintah Daerah Provinsi Sulawesi Tengah sudah dijalankan berdasarkan model yang dikembangkan Kurt Lewin yang terdiri dari unfreezing, changing, dan refreezing, dimana hasil penelitian menunjukkan bahwa aspek yang paling berpengaruh dalam membentuk manajemen perubahan di Pemerintah Daerah Provinsi Sulawesi Tengah adalah aspek refreezing yang menyatakan bahwa pegawai menciptakan/memelihara perubahan, sedangkan aspek yang paling lemah dalam mempengaruhi manajemen perubahan adalah unfreezing yang disebabkan oleh pegawai kurang siap dalam menghadapi perubahan bahkan pegawai kurang membuka diri terhadap perubahan yang dilakukan organisasi yang dalam hal ini satuan kerja perangkat daerah.
\end{abstract}

Kata kunci: manajemen, perubahan, organisasi.

\section{PENDAHULUAN}

Manajemen perubahan di Kementerian/Lembaga pemerintah dilaksanakan melalui Menteri Pendayagunaan Aparatur Negara dan Reformasi Birokrasi. Maksud manajemen perubahan tersebut untuk mengarahkan agar setiap rangkaian proses reformasi birokrasi di lingkungan pemerintah, khususnya Pemerintah Daerah Provinsi Sulawesi Tengah mencapai kinerja yang diharapkan. Tujuan manajemen perubahan adalah sebagai panduan bagi seluruh unit kerja di lingkungan pemerintah daerah maupun pusat dalam mengelola perubahan yang terjadi akibat dari reformasi birokrasi.

Perubahan lingkungan membuat perubahan bersifat kontinu dan terus berkembang, untuk itu diharapkan tumbuh kesadaran bersama bahwa setiap individu harus mengikuti serta melaksanakan perubahan, namun pada kenyataannya perubahan yang dilakukan masih sering mendapat penolakan yang mengakibatkan sulitnya menerapkan perubahan tersebut. Untuk itu 
perubahan perlu diatur dan dikontrol agar dapat dilaksanakan karena jika tidak, maka pelaksanaannya akan gagal. Nasution (2010:27) menjelaskan bahwa perubahan merupakan suatu fenomena yang harus dihadapi, namun tidak semua orang bersedia menerima kenyataan adanya perubahan sehingga berbalik resistensi atau menolak perubahan tersebut. Pandangan tersebut memberikan makna bahwa perubahan harus dihadapi meskipun perubahan terkadang masih juga ditolak.

Manajemen perubahan yang dilaksanakan di satuan kerja perangkat daerah (SKPD) di lingkungan Pemerintah Daerah Sulawesi Tengah terjadi pada 11 (sebelas) dari 29 (dua puluh sembilan) SKPD yang ada. SKPD yang mengalami perubahan terjadi pada perubahan struktur organisasi. Hal tersebut dikarenakan tuntutan reformasi birokrasi pemerintah daerah sesuai dengan visi misi pemerintah daerah yang menghendaki penguatan kelembagaan perangkat daerah perlu dilakukan agar tercapai optimalisasi pelaksanaan tugas dan fungsi perangkat daerah dalam mewujudkan tujuan pembangunan di daerah serta untuk memenuhi tuntutan masyarakat akan kebutuhan pelayanan oleh pemerintah daerah.

Tujuan manajemen perubahan dalam Peraturan Menteri Negara Pendayagunaan Aparatur Negara dan Reformasi Birokrasi Nomor 10 Tahun 2011 tentang Pedoman Pelaksanaan Program Manajemen Perubahan adalah untuk mengubah secara sistematis dan konsisten dari sistem dan mekanisme kerja organisasi serta pola pikir dan budaya kerja individu atau unit kerja di dalamnya menjadi lebih baik sesuai dengan tujuan dan sasaran reformasi birokrasi. Pencapaian tujuan pelaksanaan manajemen perubahan di satuan kerja perangkat daerah (SKPD) di lingkungan Pemerintah Daerah Sulawesi Tengah, tentunya memerlukan berbagai dukungan baik dari internal maupun eksternal organisasi, seperti adanya dukungan organisasi, pemberdayaan dan komitmen organisasional untuk menjalankan manajemen perubahan.

Penerimaan dan penolakan terhadap perubahan memang sudah sangat tentu terjadi tergantung bagaimana persepsi yang menerima perubahan tersebut, apakah dipersepsikan secara positif atau negatif. Penerimaan dan penolakan terhadap perubahan juga disebabkan oleh dukungan organisasi yang rendah, kemampuan pegawai yang belum memadai karena belum diberdayakan, atau bahkan loyalitas pegawai yang berkurang yang diakibatkan komitmen pegawai terhadap organisasi yang menurun akibat ketidakadilan yang terjadi sehingga keinginan, kemauan, keyakinan dan nilai terhadap organisasi menjadi lemah.

Lemahnya komitmen pegawai terhadap organisasi berdampak pada manajemen perubahan yang dilaksanakan dan hal tersebut berdampak pada pencapaian hasil yang diinginkan karena rendahnya komitmen pegawai. Untuk mencapai komitmen pegawai tentunya memerlukan suatu penghargaan kepada pegawai agar dapat melakukan hal yang lebih baik, yang dilakukan dengan memberikan komitmen melalui dukungan organisasi serta melakukan pemberdayaan kepada pegawai karena hal itu akan memberikan dampak positif bagi pelaksanaan manajemen perubahan karena manajemen perubahan tersebut tidak hanya dari internal tetapi juga ada desakan dari luar organisasi yang dalam hal ini masyarakat sebagai pengguna jasa organisasi, terlebih pada SKPD yang orientasinya untuk meningkatkan pembangunan di daerah yang berdampak pada kesejahteraan masyarakat.

Berdasarkan uraian yang dikemukakan, maka perlu dilakukan penelitian dengan tujuan untuk mengetahui pelaksanaan manajemen perubahan di Pemerintah Provinsi Sulawesi Tengah. 


\section{KAJIAN LITERATURE}

\section{Manajemen Perubahan}

Manajemen perubahan merupakan sebuah topik, yang paling dekat dengan penguraian totalitas tugas seorang manajer. Hampir segala sesuatu yang dilakukan seseorang manajer hingga tingkat tertentu berkaitan dengan implementasi perubahan. Perubahan merupakan sebuah fakta kehidupan pada semua organisasi (istilah perubahan keorganisasian atau organizational change, sering ditonjolkan dalam studi tentang perilaku keorganisasian).

Manajemen perubahan menurut pandangan Potts \& LaMarsh dalam Wibowo (2012:241) sebagai suatu proses secara sistematis dalam menerapkan pengetahuan, sarana dan sumber daya yang diperlukan untuk memengaruhi perubahan pada orang yang akan terkena dampak dari proses tersebut. Pandangan tersebut menjelaskan bahwa manajemen perubahan sebagai proses sistematis dalam memanfaatkan sumber daya yang mempangaruhi perubahan.

Duck, (2001); Kotter, (1995); Judson, (1991); Guth \& MacMillan, (1986); Armenakis et al., (1993) dalam Yilmaz et al. (2013:119) menjelaskan bahwa "the change management literature asserts that the reasons behind the employee resistance in an organizational change process could be investigated via empirical methods and thus it would be possible for the managers to prevent or minimize the resistance as much as possible”. Pandangan tersebut menjelaskan bahwa literatur manajemen perubahan menegaskan bahwa alasan di balik hambatan karyawan dalam proses perubahan organisasi bisa diselidiki melalui metode empiris dan dengan demikian akan mungkin bagi manajer untuk mencegah atau meminimalkan resistensi sebanyak mungkin.

Lebih lanjut Kotter (1995) dalam Yilmaz et al. (2013:120) menyatakan bahwa "suggests that among the most committed errors during the change management process is not to provide sufficient information to the employees about the importance and urgency of change". Pandangan tersebut menunjukkan bahwa kesalahan yang paling terkait selama proses perubahan manajemen adalah tidak memberikan informasi yang cukup kepada karyawan tentang pentingnya dan mendesaknya perubahan.

Manajemen perubahan ditujukan untuk memberikan solusi yang diperlukan dengan sukses dengan cara yang terorganisasi dan dengan metode melalui pengelolaan dampak perubahan pada orang yang terlibat di dalamnya. Sementara itu, perubahan selalu dimulai dengan inisiatif pandangan pada hasil positif. Hambatan paling umum untuk keberhasilan perubahan adalah resistensi manusia, yang menyebabkan resistensi dan perubahan terjadi lebih cepat dan lancar. Pendekatan dalam manajemen perubahan adalah, pertama mengidentifikasi siapa, di antara mereka yang terkena dampak perubahan, yang mungkin menolak perubahan; kedua, menelusuri sumber, tipe dan tingkat resistensi perubahan yang mungkin ditemukan; ketiga, mendesain strategi yang efektif untuk mengurangi resistensi tersebut.

\section{Tingkat dan Tahapan Perubahan}

Ada dua macam metode untuk menganalisis tingkat-tingkat perubahan keorganisasian. Salah satu metode adalah mempelajari tingkat-tingkat individu kelompok dan tingkat keorganisasian, dan metode kedua adalah mempelajari tingkat perubahan yang diperlukan pada kelompok yang dipengarahi oleh perubahan tersebut. Kombinasi antara tingkat dan derajat atau tingkat perubahan menghasilkan sebuah matriks hubungan-hubungan tersebut. 
Tabel 1 Contoh Interaksi Antara Tingkat-Tingkat dan Derajat Perubahan

TINGKAT-TINGKAT PERUBAHAN

\begin{tabular}{|c|c|c|c|c|}
\hline \multirow{4}{*}{ 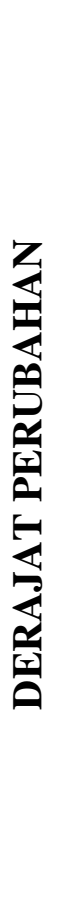 } & \multirow[b]{2}{*}{ Kecil } & INDIVIDUAL & KELOMPOK & ORGANISASI \\
\hline & & $\begin{array}{l}\text { Promosi } \\
\text { individu- } \\
\text { individu }\end{array}$ & $\begin{array}{l}\text { Tambahan } \\
\text { karya baru } \\
\text { pada } \\
\text { kelompok } \\
\text { yang ada }\end{array}$ & $\begin{array}{l}\text { Ciptakan } \\
\text { departemen staf } \\
\text { baru }\end{array}$ \\
\hline & Menengah & $\begin{array}{l}\text { Program } \\
\text { pelatihan } \\
\text { untuk }\end{array}$ & $\begin{array}{l}\text { Leburkan } \\
\text { kelompok- } \\
\text { kelompok }\end{array}$ & $\begin{array}{l}\text { Pengurangan } \\
\text { angkatan kerja }\end{array}$ \\
\hline & Besar & Ganti C.E.O & $\begin{array}{l}\text { Bubarkan } \\
\text { kelompok } \\
\text { kerja }\end{array}$ & $\begin{array}{l}\text { Restrukturisasi } \\
\text { organisasi } \\
\text { secara besar- } \\
\text { besaran }\end{array}$ \\
\hline
\end{tabular}

Sumber: Gray, Starke, 1984:553 dalam Winardi (2010:61).

Selain tingkat perubahan, selanjutnya dapat pula dilihat tahapan-tahapan perubahan, sebagaimana dikatakan Lussier (2008:511) stages in the change process:

1) Danial

When people first hear rumors through the grapevine that change is coming, they deny that it will happen at all, or to them. The 'it will affect the others, but not me' reaction is common.

2) Resistance

Once peopleget over the initial shock and realize that change is going to be a reality, they resist the change. The next section examines resistance to change and how to overcome it.

3) Exporation

When the change begins to be implemented, employeesexplore the change, often through training and better understand how it will affect them.

\section{4) Commitment}

Through exploration, employees determine their level of commitment to making the change a succcess. The le level of commitment can change over time.

Uraian terkait dengan tahapan-tahapan dalam proses perubahan dapat digambarkan bahwa tahapan-tahapan yang dimaksud di antaranya tahapan penyangkalan, perlawanan, eksplorasi dan komitmen. Kaitannya dengan penyangkalan dapat dimaknai bahwa ketika seseorang mendengar rumor selentingan untuk pertama kalinya bahwa perubahan akan terjadi, orang tersebut menyangkal bahwa hal itu akan terjadi. Maka ini akan mempengaruhi orang lain, reaksi terhadap perubahan ini jarang terjadi pada diri mereka. Tahapan perlawanan menjelaskan bahwa ketika orang-orang tekejut dan menyadari bahwa perubahan akan menjadi 
kenyataan, mereka menolak perubahan. Kemudian berikutnya mereka menguji resistensi terhadap perubahan dan bagaimana mengatasinya. Selanjutnya tahapan eksplorasi yaitu ketika perubahan mulai diterapkan, karyawan mengeksplorasi perubahan yang seringkali melalui pelatihan dan berusaha lebih memahami bagaimana hal itu akan mempengaruhi mereka. Sedangkan yang terakhir adalah tahapan komitmen yang menjelaskan bahwa komitmen melalui eksplorasi, karyawan menentukan tingkat komitmen untuk membuat perubahan itu sukses. Tingkat komitmen dapat berubah seiring waktu.

\section{Model Manajemen Perubahan}

Manajemen perubahan memiliki berbagai model untuk melihatnya, di mana melalui model-model tersebut berguna untuk mengetahui masalah perubahan yang terjadi. Pada penelitian ini hanya menjelaskan model Lewin yang dijadikan dasar dalam menganalisis manajemen perubahan.

Penting untuk diketahui bagaimana menerapkan perubahan. Ada dua model perubahan yang memberikan orientasi pro-perubahan. Pada awal tahun 1950, Kurt Lewin mengembangkan suatu teknik yang hingga saat ini masih digunakan yaitu teknik untuk mengubah perilaku, keterampilan, dan sikap masyarakat. Lewin memandang proses perubahan terdiri dari tiga langkah. Tiga langkah model perubahan menurut Lewin dalam Lussier (2008:515-516) terdiri dari:

(1) Step 1: Unfreezing

The step usually involves reducing those forces maintaining the status quo. Unfreezing is sometimes accomplished by introducing information that shows discrepancies betwen desired performance and actual performance.

(2) Step 2: Moving

This step shifts the behavior to a new level. This is the change process in which employees learn the new desirable behavior, values, and atitudes. Structural, task, technological, and people changes may take place to reach desirable performance levels.

(3) Step 3: Refreezing

The desirable performance becomes the permanent way of doing things. This is the new status quo. Refreezing often takes place through reinforcement and support for the new behavior.

Model-model perubahan menurut Lewin yang dijelaskan di atas dapat dimaknai bahwa dalam memandang perubahan Lewin melihatnya dari tiga langkah proses perubahan yang terdiri dari unfreezing, moving, dan refreezing.

Unfreezing dapat dimaknai sebagai pelibatan pengurangan kekuatan-kekuatan dalam mempertahankan status quo. Unfreezing kadang-kadang dicapai dengan memperkenalkan informasi yang menunjukkan perbedaan antara kinerja yang diharapkan dan kinerja aktual. Moving dapat dimaknai sebagai langkah yang menggeser perilaku ke tingkat yang baru. Ini merupakan proses perubahan di mana karyawan belajar perilaku baru, nilai-nilai, dan sikap yang diinginkan. Perubahan struktural, tugas, teknologi, dan perubahan orang-orang mungkin terjadi untuk mencapai tingkat kinerja yang diharapkan. Sedangkan refreezing dimaknai sebagai kinerja yang diinginkan menjadi cara permanen dalam melakukan sesuatu. Ini menjadi status quo baru. Refreezing sering terjadi melalui penguatan dan dukungan untuk perilaku yang baru. 


\section{METODE PENELITIAN}

Penelitian ini didesain metode secara deskriptif. Pertimbangan pemilihan metode tersebut, karena metode deskriptif dapat menggambarkan dimensi dari variabel penelitian yaitu manajemen perubahan.

Penentuan unit analisis merupakan penentuan subjek dalam suatu penelitian. Sejalan dengan itu, Arikunto (2010:187) menjelaskan bahwa unit analisis adalah satuan tertentu yang diperhitungkan sebagai subjek penelitian. Maksud dari hal tersebut adalah hal-hal apa yang diteliti atau dijadikan fokus penelitian. Adapun unit analisis dalam penelitian ini adalah pegawai SKPD di lingkungan Pemerintah Daerah Provinsi Sulawesi Tengah sebagai sumber data untuk diberikan angket/kuesioner penelitian atau diamati pada waktu bekerja. Selanjutnya Sekaran (2006:248) mendefinisikan unit of analysis (unit analisis) adalah tingkat pengumpulan data yang dikumpulkan selama analisis data. Pandangan tersebut menjelaskan bahwa unit analisis sebagai tingkatan dalam penelitian yang diikuti melalui tingkat pengumpulan data.

Populasi menurut Lind et al. (2011:7) adalah keseluruhan individu atau objek tertentu atau ukuran yang diperoleh dari semua individu atau objek tertentu. Sementara sampel adalah bagian dari suatu populasi. Jadi yang dimaksud dengan populasi adalah keseluruhan individu yang didapatkan dari objek tertentu. Populasi dalam penelitian ini adalah seluruh pegawai Satuan Kerja Perangkat Daerah (SKPD) di lingkungan Pemerintah Daerah Provinsi Sulawesi Tengah dengan jumlah secara kesluruhan adalah 3078 pegawai.

Sehubungan dengan pelaksanaan manajemen perubahan di instansi dan lembaga pemerintah, maka populasi yang digunakan dalam penelitian ini adalah seluruh pegawai Satuan Kerja Perangkat Daerah (SKPD) di lingkungan Pemerintah Daerah Provinsi Sulawesi Tengah yang mengalami perubahan struktur berdasarkan Peraturan Daerah Provinsi Sulawesi Tengah Nomor 09 Tahun 2012 tentang Perubahan atas Peraturan Daerah Provinsi Sulawesi Tengah Nomor 06 Tahun 2008 tentang Organisasi dan Tata Kerja Dinas-Dinas Daerah Provinsi Sulawesi Tengah yang terdiri dari 11 SKPD dengan jumlah pegawai secara keseluruhan adalah 1335 orang. Adapun rincian jumlah pegawai yang menjadi populasi penelitian ini sebagai berikut.

Tabel 1 Populasi Penelitian

\begin{tabular}{|c|l|c|c|c|c|c|}
\hline \multirow{2}{*}{ No. Satuan Kerja Perangkat Daerah (SKPD) } & \multicolumn{3}{|c|}{ Pangkat/Gol } & \multirow{2}{*}{ Jumlah } \\
\cline { 3 - 6 } & \multicolumn{1}{|c|}{ I } & II & III & IV & \\
\hline 1 & Dinas Pendidikan dan Kebudayaan Daerah & 4 & 40 & 218 & 53 & 315 \\
\hline 2 & Dinas Kesehatan Daerah & 2 & 16 & 135 & 14 & 167 \\
\hline 3 & Dinas Kehutanan Daerah & 1 & 14 & 71 & 12 & 98 \\
\hline 4 & Dinas Pertanian Daerah & 2 & 18 & 79 & 12 & 111 \\
\hline 5 & Dinas Pariwisata dan Ekonomi Kreatif & 0 & 15 & 66 & 11 & 92 \\
\hline 6 & Dinas Koperasi, UMKM, Perindustrian, dan Perdagangan Daerah & 1 & 11 & 132 & 16 & 160 \\
\hline 7 & Dinas Perhubungan Daerah & 2 & 12 & 67 & 13 & 94 \\
\hline 8 & Dinas Komunikasi dan Informatika Daerah & 2 & 17 & 79 & 14 & 112 \\
\hline 9 & Dinas Bina Marga Daerah & 1 & 14 & 37 & 10 & 62 \\
\hline 10 & Dinas Sumber Daya Air Daerah & 0 & 16 & 35 & 9 & 60 \\
\hline 11 & Dinas Cipta Karya, Perumahan dan Tata Ruang Daerah & 2 & 15 & 36 & 11 & 64 \\
\hline Total Jumlah & $\mathbf{1 7}$ & $\mathbf{1 8 8}$ & $\mathbf{9 5 5}$ & $\mathbf{1 7 5}$ & $\mathbf{1 3 3 5}$ \\
\hline
\end{tabular}

Pengambilan sampel untuk jumlah pegawai yang diteliti menggunakan rumus dari Taro Yamane dalam Riduwan (2010:65) sebagai berikut: 


$$
\mathrm{n}=\frac{\mathrm{N}}{\mathrm{N} \cdot \mathrm{d}^{2}+1}
$$

Keterangan:

$\mathrm{n}=$ Jumlah Sampel

$\mathrm{N}=$ Jumlah Populasi

$\mathrm{d}^{2}=$ Presisi (ditetapkan $5 \%$ )

Maka besarnya sampel dapat dihitung sebagai berikut.

$$
\mathrm{n}=\frac{1335}{1335 \cdot 0,05^{2}+1}=\frac{1335}{1335 \cdot 0,0025+1}=\frac{1335}{4,33}=308,31 \approx 308
$$

Selanjutnya prosedur pengambilan sampel pada penelitian ini menggunakan probability sampling yaitu dengan teknik stratified random sampling. Nazir (2011:291) menjelaskan bahwa stratified random sampling adalah sampel yang ditarik dengan memisahkan elemenelemen populasi dalam kelompok-kelompok yang tidak overlapping yang disebut strata, dan kemudian memilih sebuah sampel secara random dari setiap stratum. Secara kumulatif, jumlah sampel pada penelitian ini dapat dilihat dari rician Tabel 2 berikut.

Tabel 2 Sampel Penelitian

\begin{tabular}{|c|l|c|c|c|c|c|}
\hline \multirow{2}{*}{ No. Satuan Kerja Perangkat Daerah (SKPD) } & \multicolumn{3}{|c|}{ Pangkat/Gol } & \multirow{2}{*}{ Jumlah } \\
\cline { 3 - 5 } & & I & II & III & IV & \\
\hline 1 & Dinas Pendidikan dan Kebudayaan Daerah & 1 & 9 & 50 & 12 & 73 \\
\hline 2 & Dinas Kesehatan Daerah & 1 & 4 & 31 & 3 & 39 \\
\hline 3 & Dinas Kehutanan Daerah & 1 & 3 & 16 & 3 & 23 \\
\hline 4 & Dinas Pertanian Daerah & 0 & 4 & 18 & 3 & 26 \\
\hline 5 & Dinas Pariwisata dan Ekonomi Kreatif & 0 & 3 & 15 & 3 & 21 \\
\hline 6 & Dinas Koperasi, UMKM, Perindustrian, dan Perdagangan & 0 & 3 & 30 & 4 & 37 \\
\hline 7 & Dinas Perhubungan Daerah & 1 & 3 & 15 & 3 & 22 \\
\hline 8 & Dinas Komunikasi dan Informatika Daerah & 1 & 4 & 18 & 3 & 26 \\
\hline 9 & Dinas Bina Marga Daerah & 0 & 3 & 9 & 2 & 14 \\
\hline 10 & Dinas Sumber Daya Air Daerah & 0 & 4 & 8 & 2 & 14 \\
\hline 11 & Dinas Cipta Karya, Perumahan dan Tata Ruang Daerah & 1 & 3 & 8 & 3 & 15 \\
\hline Total Jumlah & $\mathbf{6}$ & $\mathbf{4 3}$ & $\mathbf{2 1 8}$ & $\mathbf{4 1}$ & $\mathbf{3 0 8}$ \\
\hline
\end{tabular}

\section{HASIL DAN PEMBAHASAN}

\section{Pelaksanaan Manajemen Perubahan di Pemerintah Daerah Provinsi Sulawesi Tengah}

Hasil analisis berikut secara deskriptif menggambarkan tanggapan responden terhadap dimensi melalui item pertanyaan/pernyataan dari variabel manajemen perubahan dengan dimensi unfreezing, changing, dan refreezing.

\section{1) Dimensi Unfreezing}

Dimensi unfreezing pada penelitian ini diukur berdasarkan 2 (dua) indikator penelitian yang dilihat dari perilaku dan sikap sesuai organisasi serta kesiapan individu dan membuka diri. Hasil analisis deskriptif dari dimensi dan indikator tersebut dapat dilihat berikut. 
Tabel 3 Deskriptif Dimensi Unfreezing

\begin{tabular}{|c|c|c|c|c|c|c|c|c|c|}
\hline \multirow{3}{*}{ Skala } & \multicolumn{6}{|c|}{ Item Pertanyaan/Pernyataan } & \multirow{2}{*}{\multicolumn{3}{|c|}{ Dimensi Kumulatif }} \\
\hline & \multicolumn{3}{|c|}{1} & \multicolumn{3}{|c|}{2} & & & \\
\hline & $\mathbf{F}$ & $\%$ & Skor & $\mathbf{F}$ & $\%$ & Skor & f & $\%$ & Skor \\
\hline 1 & 0 & 0,0 & 0 & 0 & 0,0 & 0 & 0 & 0,0 & 0 \\
\hline 2 & 0 & 0,0 & 0 & 0 & 0,0 & 0 & 0 & 0,0 & 0 \\
\hline 3 & 11 & 3,6 & 33 & 12 & 3,9 & 36 & 23 & 3,7 & 69 \\
\hline 4 & 181 & 58,8 & 724 & 196 & 63,6 & 784 & 377 & 61,2 & 1508 \\
\hline 5 & 116 & 37,7 & 580 & 100 & 32,5 & 500 & 216 & 35,1 & 1080 \\
\hline Total Capaian & 308 & 100 & 1337 & 308 & 100 & 1320 & 616 & 100 & 2657 \\
\hline \multicolumn{3}{|l|}{ Skor Max } & 1540 & & & 1540 & & & 3080 \\
\hline \multicolumn{3}{|l|}{ Total Skor $(\%)$} & 86,8 & & & 85,7 & & & 86,3 \\
\hline
\end{tabular}

Sumber: Hasil Olahan Data Penelitian.

Berdasarkan analisis deskriptif pada Tabel 3 secara kumulatif dimensi unfreezing dapat diinterpretasikan pada kriteria sangat optimal (86,5\%). Dimensi tersebut sangat dipengaruhi oleh item pertanyaan/pernyataan nomor 1 dengan indikator perilaku dan sikap sesuai organisasi yang memiliki persentase total skor tertinggi (86,8\%), sedangkan item pertanyaan/pernyataan nomor 2 dengan indikator kesiapan individu dan membuka diri memiliki persentase total skor rendah $(85,7 \%)$. Hasil tersebut menjelaskan bahwa pegawai selalu menunjukkan perilaku kerja dan sikap yang sesuai dengan keinginan organisasi, namun pegawai kurang siap dalam menghadapi perubahan bahkan pegawai kurang membuka diri terhadap perubahan yang dilakukan organisasi.

2) Dimensi Changing

Dimensi changing pada penelitian ini dilihat dari 2 (dua) item pertanyan/pernyataan dengan indikator penelitian yang terdiri dari adanya rekomendasi perubahan dan pembelajaran melalaui informasi. Dimensi dan indikator tersebut dapat dilihat dari hasil analisis deskriptif berikut.

Tabel 4 Deskriptif Dimensi Changing

\begin{tabular}{|c|c|c|c|c|c|c|c|c|c|}
\hline \multirow{3}{*}{ Skala } & \multicolumn{6}{|c|}{ Item Pertanyaan/Pernyataan } & \multirow{2}{*}{\multicolumn{3}{|c|}{ Dimensi Kumulatif }} \\
\hline & \multicolumn{3}{|c|}{3} & \multicolumn{3}{|c|}{4} & & & \\
\hline & $\mathbf{F}$ & $\%$ & Skor & $\mathbf{F}$ & $\%$ & Skor & $\mathbf{f}$ & $\%$ & Skor \\
\hline 1 & 0 & 0,0 & 0 & 0 & 0,0 & 0 & 0 & 0,0 & 0 \\
\hline 2 & 0 & 0,0 & 0 & 0 & 0,0 & 0 & 0 & 0,0 & 0 \\
\hline 3 & 16 & 5,2 & 48 & 26 & 8,4 & 78 & 42 & 6,8 & 126 \\
\hline 4 & 168 & 54,5 & 672 & 164 & 53,2 & 656 & 332 & 53,9 & 1328 \\
\hline 5 & 124 & 40,3 & 620 & 118 & 38,3 & 590 & 242 & 39,3 & 1210 \\
\hline Total Capaian & 308 & 100 & 1340 & 308 & 100 & 1324 & 616 & 100 & 2664 \\
\hline \multicolumn{3}{|l|}{ Skor Max } & 1540 & & & 1540 & & & 3080 \\
\hline \multicolumn{3}{|l|}{ Total Skor (\%) } & 87,0 & & & 86,0 & & & 86,5 \\
\hline
\end{tabular}

Sumber: Hasil Olahan Data Penelitian.

Hasil deskriptif pada Tabel 4 menunjukkan bahwa secara kumulatif dimensi changing berada pada kriteria interpretasi sangat optimal (86,5\%), ini artinya bahwa pegawai di 11 SKPD di jajaran Pemerintah Daerah Provinsi Sulawesi Tengah diberikan pemberdayaan secara optimal, di mana dalam Tabel 4 tersebut menunjukkan bahwa item 
pertanyaan/pernyataan nomor 3 sangat mempengaruhi dimensi changing yaitu adanya rekomendasi perubahan yang memiliki persentase total skor tertinggi $(87,0 \%)$, sedangkan item pertanyaan/pernyataan nomor 4 tentang pembelajaran melalui informasi memiliki persentase total skor rendah $(86,0)$. Hasil tersebut menunjukkan bawha bahwa pegawai dapat menerima rekomendasi atas perubahan yang terjadi dalam organisasi, baik dalam kehidupan pegawai maupun organisasi, namun pegawai kurang berusaha belajar terhadap hal-hal yang baru terkait dengan perubahan dalam organisasi.

\section{3) Dimensi Refreezing}

Dimensi refreezing pada penelitian ini dilihat berdasarkan 2 (dua) item pertanyaan/pernyatan dengan indikator penelitian yang dapat dilihat dari mengembangkan perubahan dan menciptakan/memelihara perubahan. Hasil analisis deskriptif dari dimensi dan indikator tersebut dapat dilihat berikut.

Tabel 5 Deskriptif Dimensi Refreezing

\begin{tabular}{|c|c|c|c|c|c|c|c|c|c|}
\hline \multirow{3}{*}{ Skala } & \multicolumn{6}{|c|}{ Item Pertanyaan/Pernyataan } & \multirow{2}{*}{\multicolumn{3}{|c|}{ Dimensi Kumulatif }} \\
\hline & \multicolumn{3}{|c|}{5} & \multicolumn{3}{|c|}{6} & & & \\
\hline & $\mathbf{F}$ & $\%$ & Skor & $\mathbf{F}$ & $\%$ & Skor & $\mathbf{f}$ & $\%$ & Skor \\
\hline 1 & 0 & 0,0 & 0 & 0 & 0,0 & 0 & 0 & 0,0 & 0 \\
\hline 2 & 0 & 0,0 & 0 & 0 & 0,0 & 0 & 0 & 0,0 & 0 \\
\hline 3 & 10 & 3,2 & 30 & 15 & 4,9 & 45 & 25 & 4,1 & 75 \\
\hline 4 & 180 & 58,4 & 720 & 143 & 46,4 & 572 & 323 & 52,4 & 1292 \\
\hline 5 & 118 & 38,3 & 590 & 150 & 48,7 & 750 & 268 & 43,5 & 1340 \\
\hline Total Capaian & 308 & 100 & 1340 & 308 & 100 & 1367 & 616 & 100 & 2707 \\
\hline \multicolumn{3}{|l|}{ Skor Max } & 1540 & & & 1540 & & & 3080 \\
\hline \multicolumn{3}{|l|}{ Total Skor $(\%)$} & 87,0 & & & 88,8 & & & 87,9 \\
\hline
\end{tabular}

Sumber: Hasil Olahan Data Penelitian.

Hasil analisis deskriptif dalam Tabel 5 menunjukkan bahwa secara kumulatif dimensi refreezing berada pada kriteria interpretasi sangat optimal $(87,9 \%)$. Hasil tersebut sangat dipengaruhi oleh item pertanyaan/pernyataan nomor 6 yaitu menciptakan/memelihara perubahan yang memiliki persentase total skor tertinggi $(88,8 \%)$, sedangkan item pertanyaan/pernyataan nomor 5 tentang mengembangkan perubahan memiliki persentase total skor yang lebih rendah $(87,0 \%)$. Hasil tersebut dapat dimaknai bahwa hasil kerja yang diinginkan dapat tercapai jika pegawai dalam organisasi menciptakan/memelihara perubahan, namun hal tersebut kurang berhasil jika pegawai dalam organisasi kurang mampu dalam mengembangkan perubahan melalui perilaku dan sikap untuk bertindak dalam organisasi.

Berdasarkan hasil secara keseluruhan kaitannya dengan variabel manajemen perubahan yang terdiri dari dimensi unfreezing, changing, dan refreezing, menunjukkan bahwa dimensi yang paling berpengaruh dalam membentuk manajemen perubahan adalah dimensi refreezing yang menyatakan bahwa pegawai menciptakan/memelihara perubahan, sedangkan dimensi yang paling lemah dalam mempengaruhi manajemen perubahan adalah dimensi unfreezing yang disebabkan oleh pegawai kurang siap dalam menghadapi perubahan bahkan pegawai kurang membuka diri terhadap perubahan yang dilakukan organisasi meskipun mereka memelihara dan menjaga perubahan yang dilakukan. 


\section{KESIMPULAN DAN SARAN}

\section{Kesimpulan}

Berdasarkan hasil pembahasan yang dilakukan, disimpulkan bahwa pelaksanaan manajemen perubahan di Pemerintah Daerah Provinsi Sulawesi Tengah sudah dijalankan berdasarkan model yang dikembangkan Kurt Lewin yang terdiri dari unfreezing, changing, dan refreezing, dimana hasil penelitian menunjukkan bahwa aspek yang paling berpengaruh dalam membentuk manajemen perubahan di Pemerintah Daerah Provinsi Sulawesi Tengah adalah aspek refreezing yang menyatakan bahwa pegawai menciptakan/memelihara perubahan, sedangkan aspek yang paling lemah dalam mempengaruhi manajemen perubahan adalah unfreezing yang disebabkan oleh pegawai kurang siap dalam menghadapi perubahan bahkan pegawai kurang membuka diri terhadap perubahan yang dilakukan organisasi yang dalam hal ini satuan kerja perangkat daerah (SKPD) meskipun mereka memelihara dan menjaga perubahan yang dilakukan.

\section{Saran}

Menindaklanjuti kesimpulan dari penelitian ini, maka disarankan kepada pihak terkait yang dalam hal ini pegawai di satuan kerja perangkat daerah (SKPD) Pemerintah Daerah Provinsi Sulawesi Tengah agar lebih siap dan membuka diri dalam menghadapi perubahan, karena perubahan yang dilakukan bertujuan untuk pengembangan dan peningkatan kinerja organisasi.

\section{REFERENSI}

Arikunto, Suharsimi. 2010. Prosedur Penelitian Suatu Pendekatan Praktik. Jakarta: Rineka Cipta.

Lind, Douglas A., William G. Marchal \& Samuel A. Wathen. 2011. Teknik-Teknik Statistika dalam Bisnis dan Ekonomi Menggunakan Kelompok Data Global. Edsi 13. Jakarta: Salemba Empat.

Lussier, Robert N. 2008. Human Relations in Organizations, Applications and Skill Building. Seventh edition. Americas: Published by McGraw-Hill.

Nasution, M. Nur. 2010. Manajemen Perubahan. Bogor: Ghalia Indonesia.

Nazir, Moh. 2011. Metode Penelitian. Bogor: Ghalia Indonesia.

Peraturan Menteri Negara Pendayagunaan Aparatur Negara dan Reformasi Birokrasi Nomor 10 Tahun 2011 tentang Pedoman Pelaksanaan Program Manajemen

Peraturan Daerah Provinsi Sulawesi Tengah Nomor 09 Tahun 2012 tentang Perubahan atas Peraturan Daerah Provinsi Sulawesi Tengah Nomor 06 Tahun 2008 tentang Organisasi dan Tata Kerja Dinas-Dinas Daerah Provinsi Sulawesi Tengah

Riduwan. 2010. Metode dan Teknik Menyusun Tesis. Bandung: Alfabeta.

Sekaran, Uma. 2006. Research Methods For Business. Metodologi Penelitian untuk Bisnis. Buku 2 Edisi 4. Jakarta: Salemba empat.

Wibowo. 2012. Manajemen Perubahan. Edisi Ketiga. Jakarta: Rajawali Pers.

Winardi, J. 2010. Manajemen Perubahan (Management of Change). Edisi Pertama Cetakan Keempat. Jakarta: Prenada Media Group.

Yilmaz, Sefer., Huzeyin Ozgen, Recai Akyel. 2013. The Impact of Change Management on The Attitudes of Turkish Security Managers Towards Change. Journal of Organizational Change. Vol. 26, No. 1. Halaman: 117-138. 